Jasmina Dedić, Srdjan Jović*, Jelena Djokić

University of Prishtina, Faculty of Technical Sciences, Kosovska Mitrovica, Serbia
Scientific paper

ISSN 0351-9465, E-ISSN 2466-2585

UDC: $630 * 43.001 .18$

doi:10.5937/zasmat1901058D

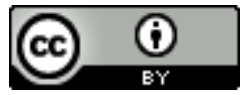

Zastita Materijala $60(1)$

$58-63$ (2019)

\title{
Analyses of burned area of forest by adaptive neuro-fuzzy approach
}

\begin{abstract}
Burned area of forest may be developed based on different factors. In this investigation the burned area of forest was analyzed by computational intelligence approach. The main goal was to analyze the influence of eight inputs on the burned area of forest. The method of ANFIS (adaptive neuro fuzzy inference system) was applied to the data. Eight inputs are considered: FFMC, DMC, $D C$, ISI, temp, RH, wind, rain. The ANFIS process was implemented to detect the dominant factors which affect the forecasting of the burned area of forest.
\end{abstract}

Keywords: ANFIS; forecasting; the burned area of forest.

\section{INTRODUCTION}

A number of studies have examined controls on high severity fire occurrence, but none have yet determined what controls the extent of high severity fire [1,2]. Global burned are algorithms provide valuable information for climate modellers since fire disturbance is responsible of a significant part of the emissions and their related impact on humans [3]. Forest fires have environmental impacts that create economic problems as well as ecological damage. Developing a means to predict the possible size of a fire shortly after it first breaks out has the potential to guide proper resource allocation for improved fire control and was the main motivation of this research [4]. Fire is an integral Earth system process, playing an important role in the distribution of terrestrial ecosystems and affecting the carbon cycle at the global scale [5] Fire Weather Index (FWI) results in article [6] suggested the predicted increase in extreme summer heat events with global warming could increase burned area as firefighting resources are stretched beyond capacity. Managers of wildfireprone landscapes in the Euro-Mediterranean region would greatly benefit from fire weather predictions a few months in advance, and particularly from the reliable prediction of extreme fire seasons [7].

${ }^{*}$ Corresponding author: Srdjan Jović

E-mail: srdjanjovic2016@hotmail.com

Paper received: 10. 11. 2018.

Paper accepted: 08. 12. 2018.

Paper is available on the website: www.idk.org.rs/journal
A fire danger rating system should supply an objective answer to the question: 'What is the probability of a fire starting, spreading and doing damage today?' It enables fire managers to properly assess the levels of preparedness and the suppression resources needed to keep fire losses to a minimum. A fire danger rating system measures the variable elements which cause day to day changes in fire risk, and interprets the information gained. The information is used to:

- define the fire season

- determine appropriate fire prevention measures

- assess the likelihood of fire occurring

- determine fire suppression response and resources

- inform the public

- make decisions to close areas at high risk

- issue or cancel burn permits

- plan and conduct controlled burns

In this investigation adaptive neuro-fuzzy inference system (ANFIS) [8], was used to analyze burned area of forest based on three Fuel Moisture Codes and one Fire Behaviour Indice

\section{METHODOLOGY}

The Fire Weather Index (FWI) System is the first part of the Canadian Forest Fire Danger Rating System (CFFDRS) introduced into New Zealand in 1980. It has proved to be a suitable fire danger rating system for this country. The FWI was evaluated for several seasons before it was 
introduced for the 1980-81 fire season. The FWI is based on weather readings taken at noon standard time and rates fire danger at the midafternoon peak from 2:00 - 4:00 pm. Weather readings required are:

- $\quad$ Air temperature (in the shade)

- Relative Humidity (in the shade)

- Wind speed (at 10 metres above ground level for an average over 10 minutes)

- Rainfall (For the previous 24 hours)

The Fire Weather Index has six components:

Three Fuel Moisture Codes

Fine Fuel Moisture Code (FFMC)

Duff Moisture Code (DMC)

Drought Code (DC)

Three Fire Behaviour Indices

Initial Spread index (ISI)

Build Up Index (BUI)

Fire Weather Index (FWI)

The main goal was to analyze the influence of FFMC, DMC, DC, ISI, temp, $\mathrm{RH}$, wind, rain on the burned area of forest. Table 1 shows input parameters which are used in this investigation.

Table 1. Input parameters

Tabela 1. Ulazni parametri

\begin{tabular}{|c|c|}
\hline Inputs & Parameters description \\
\hline in1 & Fine Fuel Moisture Code (FFMC) \\
\hline in2 & Duff Moisture Code (DMC) \\
\hline in3 & Drought Code (DC) \\
\hline in4 & Initial Spread index (ISI) \\
\hline in5 & temp \\
\hline in6 & RH \\
\hline in7 & wind \\
\hline in8 & rain \\
\hline
\end{tabular}

\subsection{ANFIS methodology}

Fuzzy inference system is employed of the ANFIS training and evaluation. In the process of identification of variables in the ANFIS architectures, the hybrid learning algorithms were applied. The functional signals progress until the $4^{\text {th }}$ layer whereby the hybrid learning algorithm passes. Further, the consequent variables are found by the least squares estimation. In the backward pass, the error rates circulate backwards and the premise variables are sychornized through the gradient decline order.

\section{RESULTS}

\subsection{Evaluating accuracy indices}

Forecasting performances of proposed model were presented as root means square error (RMSE), Coefficient of determination $\left(\mathrm{R}^{2}\right)$ and Pearson coefficient $(r)$. These statistics are defined as follows:

1) root-mean-square error (RMSE)

$$
R M S E=\sqrt{\frac{\sum_{i=1}^{n}\left(P_{i}-O_{i}\right)^{2}}{n}}
$$

2) Pearson correlation coefficient ( $r)$

$$
r=\frac{n\left(\sum_{i=1}^{n} O_{i} \cdot P_{i}\right)-\left(\sum_{i=1}^{n} O_{i}\right) \cdot\left(\sum_{i=1}^{n} P_{i}\right)}{\sqrt{\left(n \sum_{i=1}^{n} O_{i}^{2}-\left(\sum_{i=1}^{n} O_{i}\right)^{2}\right) \cdot\left(n \sum_{i=1}^{n} P_{i}^{2}-\left(\sum_{i=1}^{n} P_{i}\right)^{2}\right)}}
$$

3) coefficient of determination $\left(R^{2}\right)$

$$
R^{2}=\frac{\left[\sum_{i=1}^{n}\left(O_{i}-\overline{O_{i}}\right) \cdot\left(P_{i}-\overline{P_{i}}\right)\right]^{2}}{\sum_{i=1}^{n}\left(O_{i}-\overline{O_{i}}\right) \cdot \sum_{i=1}^{n}\left(P_{i}-\overline{P_{i}}\right)}
$$

where $P_{i}$ and $O_{i}$ are known as the experimental and forecast values, respectively, and $n$ is the total number of test data.

\subsection{ANFIS results}

A search was performed from the given inputs to choose the combinations of inputs (Table 1) which has the most impact on the burned area of forest. The parameters' impacts in the forecasting of the output was determined, as presented in Table 2. The input with the lowest training error (trn) has the most relevance to the burned area of forest. According the Table 2 the input parameter 6 has the highest influence on the burned area of forest forecasting since the input 6 has the smallest training error (trn). Table 2 shows also the numerical results for two and three parameters influence on the burned area of forest. 
Table 2. Parameters influence on forecasting of the burned area of forest

Tabela 2. Uticaj parametara na predviđanje površine požara u šumi

\begin{tabular}{|c|c|c|}
\hline $\begin{array}{c}\text { in1 }-->\operatorname{trn}=70.8776 \\
\text { chk }=55.1682\end{array}$ & in1 in2 --> trn $=70.5966$, chk $=80.0445$ & in1 in2 in3 --> trn=70.1852, chk=68.4009 \\
\hline $\begin{array}{c}\text { in2 }-->\operatorname{trn}=70.7016 \\
\text { chk }=55.5331\end{array}$ & in1 in3 --> trn=70.6552, chk=58.2432 & in1 in2 in4 --> trn=70.1788, chk=89.7701 \\
\hline $\begin{array}{c}\text { in3 }-->\operatorname{trn}=70.7032 \\
\text { chk }=55.4199\end{array}$ & in1 in4 --> trn=70.7250, chk=55.4623 & in 1 in2 in5 --> trn $=70.0338$, chk $=108.7148$ \\
\hline $\begin{array}{c}\text { in4 }-->\operatorname{trn}=70.8998 \\
\text { chk }=55.1725\end{array}$ & in1 in5 --> trn=70.4987, chk=65.6365 & in1 in2 in6 --> trn=69.8834, chk=64.2655 \\
\hline $\begin{array}{c}\text { in5 }-->\operatorname{trn}=70.6241 \\
\text { chk }=54.7341\end{array}$ & in1 in6 --> trn=70.4514, chk=55.7053 & in1 in2 in7 --> trn=69.9907, chk=144.9729 \\
\hline $\begin{array}{c}\text { in } 6 \text {--> trn=70.5134, } \\
\text { chk }=55.4872\end{array}$ & in1 in7 --> trn=70.5419, chk=63.0611 & in1 in2 in8 --> trn=70.5862, chk=77.8195 \\
\hline $\begin{array}{c}\text { in7 }-->\operatorname{trn}=70.6711 \\
\text { chk }=55.4003\end{array}$ & in1 in8 --> trn=70.8545, chk=55.2624 & in1 in3 in4 --> trn=70.1868, chk=75.1055 \\
\hline \multirow[t]{25}{*}{$\begin{array}{c}\text { in8 }-->\operatorname{trn}=70.9575 \\
\text { chk }=59.5532\end{array}$} & in2 in3 --> trn=70.2993, chk=56.4595 & in1 in3 in5 --> trn=70.0067, chk=108.6739 \\
\hline & in2 in4 --> trn=70.4862, chk=56.3718 & in1 in3 in6 --> trn=69.9181, chk=206.8819 \\
\hline & in2 in5 --> trn=70.2399, chk=56.0975 & in1 in3 in7 --> trn=70.0876, chk=64.2259 \\
\hline & in2 in6 --> trn=70.1863, chk=55.5388 & in1 in3 in8 --> trn=70.6360, chk=57.9246 \\
\hline & in2 in7 --> trn=70.2782, chk=55.9343 & in1 in4 in5 --> trn=70.1054, chk=66.4705 \\
\hline & in2 in8 --> trn=70.6830, chk=69.3239 & in1 in4 in6 --> trn=70.0034, chk=65.7524 \\
\hline & in3 in4 --> trn=70.4386, chk=55.8630 & in1 in4 in7 --> trn=70.0656, chk=298.7084 \\
\hline & in3 in5 --> trn=70.4057, chk=55.2416 & in1 in4 in8 --> trn=70.7082, chk=55.4288 \\
\hline & in3 in6 --> trn=70.1083, chk=55.4720 & in1 in5 in6 --> trn=69.9719, chk=112.1698 \\
\hline & in3 in7 --> trn=70.2413, chk=56.0605 & in1 in5 in7 --> trn=69.6507, chk=86.9506 \\
\hline & in3 in8 $-->\operatorname{trn}=70.6841$, chk=55.4332 & in1 in5 in8 --> trn=70.4951, chk=65.3891 \\
\hline & in4 in5 --> trn=70.4467, chk=55.2043 & in1 in6 in7 --> trn=69.8960, chk=149.4115 \\
\hline & in4 in6 --> trn=70.3835, chk=55.5863 & in1 in6 in8 --> trn=70.4470, chk=55.7860 \\
\hline & in4 in7 --> trn=70.4458, chk=55.7081 & in1 in7 in8 --> trn=70.5214, chk=59.0786 \\
\hline & in4 in8 $-->\operatorname{trn}=70.8838$, chk $=59.5185$ & in2 in3 in4 --> trn=69.8389, chk=60.1344 \\
\hline & in5 in6 --> trn=70.1677, chk=55.6105 & in2 in3 in5 --> trn=69.5835, chk=57.1709 \\
\hline & in5 in7 $-->$ trn=70.0143, chk=55.0437 & in2 in3 in6 --> trn=69.5317, chk=57.1178 \\
\hline & in5 in8 $-->$ trn=70.6108, chk=54.7739 & in2 in3 in7 --> trn=69.6546, chk=57.7443 \\
\hline & in6 in7 --> trn=70.0306, chk=55.7767 & in2 in3 in8 --> trn=70.2910, chk=56.6503 \\
\hline & in6 in8 $-->\operatorname{trn}=70.5104$, chk $=56.1158$ & in2 in4 in5 --> trn=69.7771, chk=59.8863 \\
\hline & in7 in8 --> trn=70.6586, chk=55.3880 & in2 in4 in6 --> trn=69.7242, chk=56.6838 \\
\hline & & in2 in4 in7 --> trn=69.6987, chk=59.0423 \\
\hline & & in2 in4 in8 --> trn=70.4842, chk=56.3771 \\
\hline & & in2 in5 in6 --> trn=69.7615, chk=57.1683 \\
\hline & & in2 in5 in7 --> trn=69.5104, chk=56.7480 \\
\hline
\end{tabular}




\begin{tabular}{|c|c|c|}
\hline & & in2 in5 in8 --> trn=70.2345, chk=56.2462 \\
\hline & & in2 in6 in7 --> trn=69.4327, chk=55.1262 \\
\hline & & in2 in6 in8 --> trn=70.1859, chk=55.5362 \\
\hline & & in2 in7 in8 --> trn=70.2524, chk=55.8709 \\
\hline & & in3 in4 in5 --> trn=69.7581, chk=59.1198 \\
\hline & & in3 in4 in6 --> trn=69.4794, chk=58.5765 \\
\hline & & in3 in4 in7 --> trn=69.6766, chk=57.0705 \\
\hline & & in3 in4 in8 --> trn=70.4288, chk=55.8391 \\
\hline & & in3 in5 in6 --> trn=69.8140, chk=55.1576 \\
\hline & & in3 in5 in7 --> trn=69.6071, chk=56.2251 \\
\hline & & in3 in5 in8 --> trn=70.3833, chk=55.3118 \\
\hline & & in3 in6 in7 --> trn=69.3915, chk=56.2117 \\
\hline & & in3 in6 in8 --> trn=70.1058, chk=55.4898 \\
\hline & & in3 in7 in8 --> trn=70.2179, chk=56.1407 \\
\hline & & in4 in5 in6 --> trn=69.7383, chk=63.7406 \\
\hline & & in4 in5 in7 --> trn=69.3746, chk=64.1600 \\
\hline & & in4 in5 in8 --> trn=70.4373, chk=55.1902 \\
\hline & & in4 in6 in7 --> trn=69.6787, chk=56.5632 \\
\hline & & in4 in6 in8 --> trn=70.3693, chk=55.7489 \\
\hline & & in4 in7 in8 --> trn=70.4333, chk=55.7438 \\
\hline & & in5 in6 in7 --> trn=69.2943, chk=56.3454 \\
\hline & & in5 in6 in8 --> trn=70.1663, chk=55.5662 \\
\hline & & in5 in7 in8 --> trn=69.9925, chk=55.1766 \\
\hline & & in6 in7 in8 --> trn=70.0279, chk=56.0244 \\
\hline
\end{tabular}

Figure 1 shows ANFIS forecasting of the burned area of forest for the optimal combinations of the selected input parameters.

\section{ANFIS prediction of area for one input}

50

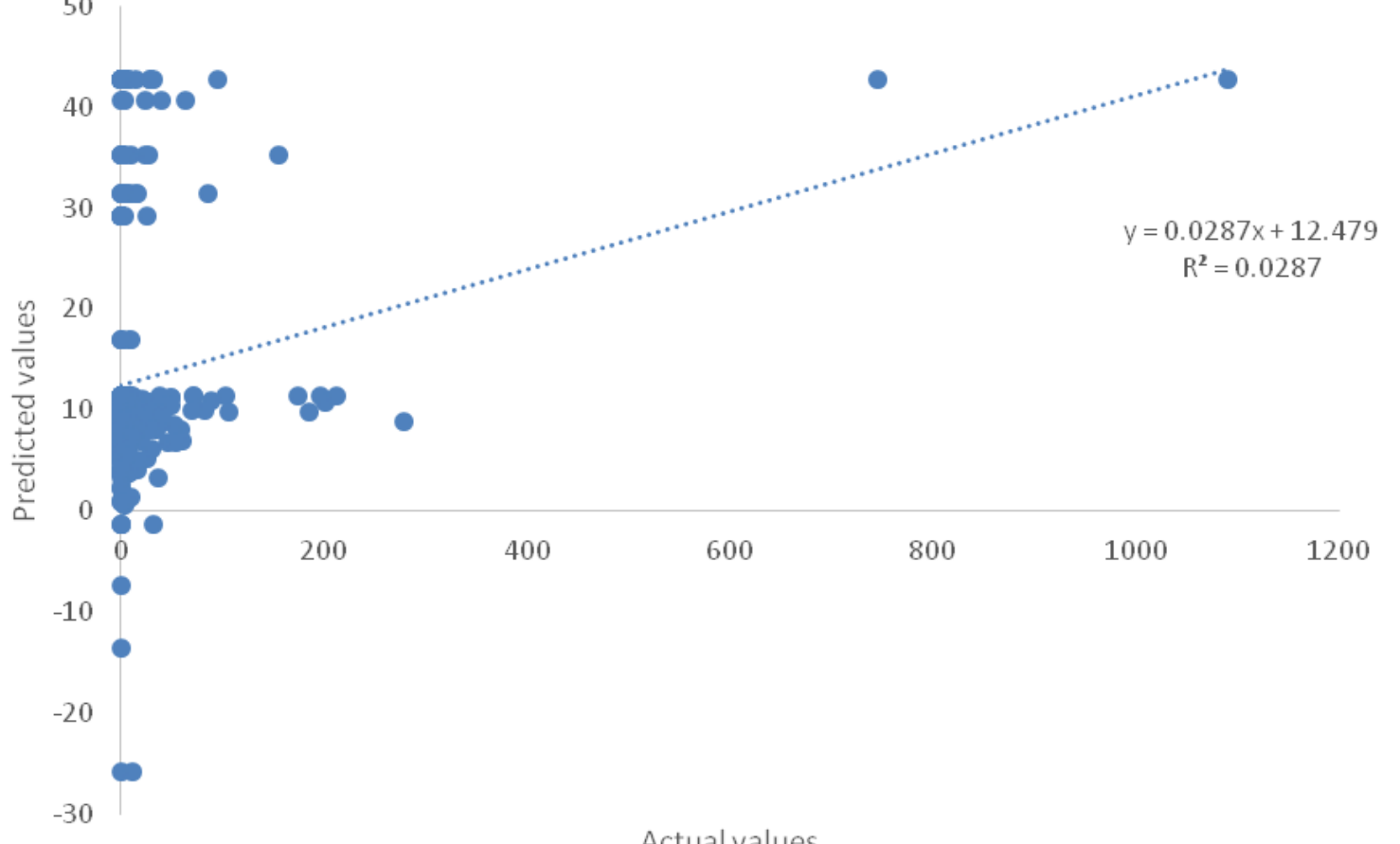

Actual values 


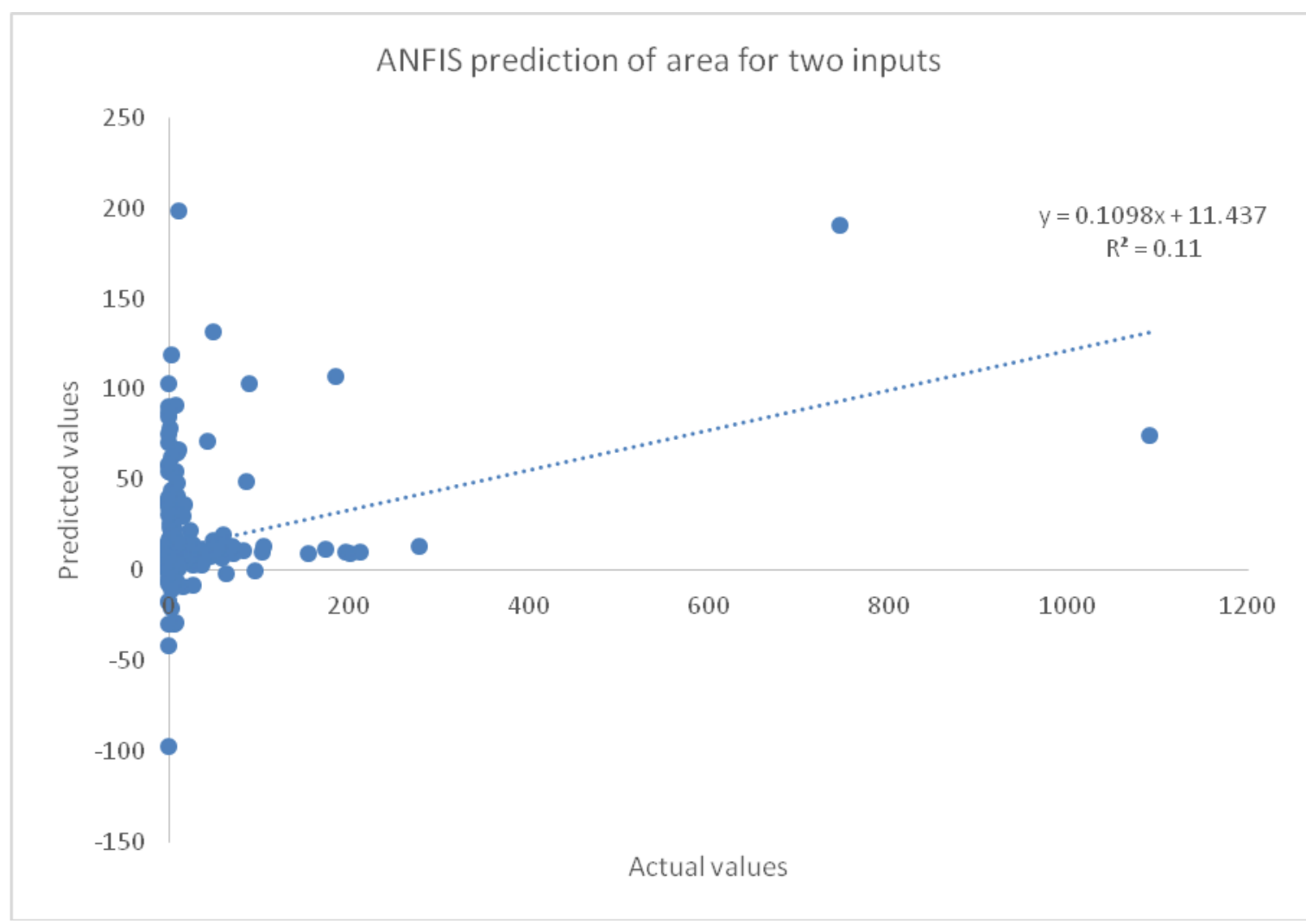

(b)

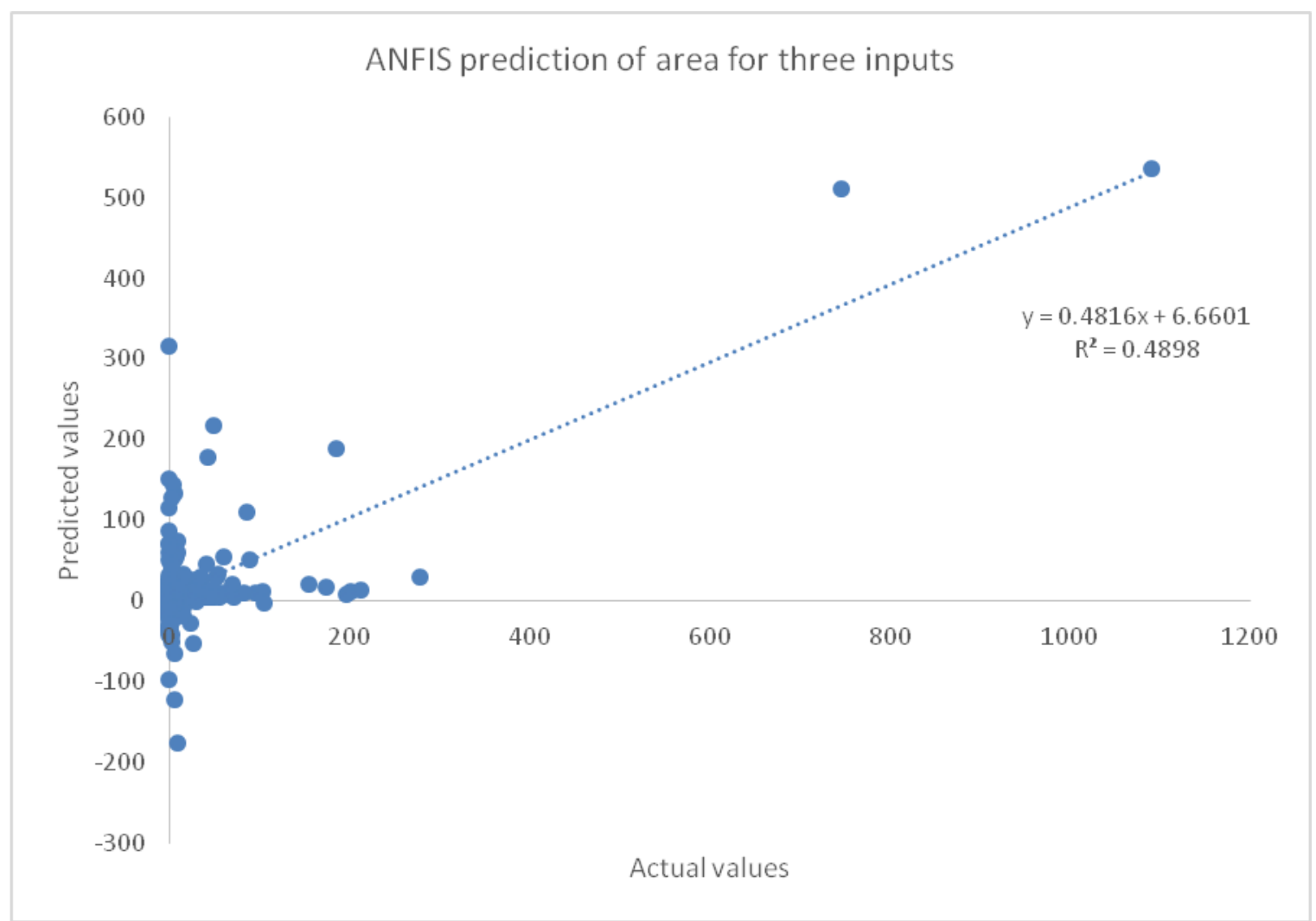

(c)

Figure 1: ANFIS plots for forecasting of burned area of forest for (a) one input, (b) two inputs (c) three inputs

Slika 1: ANFIS grafici predviđanja povšine požara u šumi za (a) jedan ulaz, (b) dva ulaza (c) tri ulaza 
Table 3 summarize the forecasting accuracy results for the selected inputs for the forecasting of the burned area of forest.

Table 3. Statistical results for forecasting of the burned area of forest for the three selected combinations

Tabela 3. Statistički rezultati predikcije površine požara $u$ šumi

\begin{tabular}{|l|c|c|}
\hline \multirow{3}{*}{$\begin{array}{l}\text { burned area of forest } \\
\text { forecasting for one input }\end{array}$} & $r$ & 0.169341 \\
\cline { 2 - 3 } & $\mathrm{R}^{2}$ & 0.0287 \\
\cline { 2 - 3 } & $\mathrm{RMSE}$ & 62.67577 \\
\hline \multirow{3}{*}{$\begin{array}{l}\text { burned area of forest } \\
\text { forecasting for two inputs }\end{array}$} & $\mathrm{r}$ & 0.331658 \\
\cline { 2 - 3 } & $\mathrm{R}^{2}$ & 0.11 \\
\cline { 2 - 3 } & $\mathrm{RMSE}$ & 59.99479 \\
\hline \multirow{3}{*}{$\begin{array}{l}\text { burned area of forest } \\
\text { forecasting for three inputs }\end{array}$} & $\mathrm{r}$ & 0.699839 \\
\cline { 2 - 3 } & $\mathrm{R}^{2}$ & 0.4898 \\
\cline { 2 - 3 } & $\mathrm{RMSE}$ & 45.43143 \\
\hline
\end{tabular}

\section{CONCLUSION}

Forecasting of the burned area of forest is complex task due to the many indicators which influence the burned area of forest. Therefore in this study was proposed an approach to overcome the forecasting difficulties of the burned area of forest by removing some parameters. The procedure is known as selection procedure and the main goal was to determine the parameters' influence on the output prediction.

\section{REFERENCES}

[1] A.R.Keyser, A.L.Westerling (2018) Predicting increasing high severity area burned for three forested regions in the western United States using extreme value theory. Forest Ecology and Management, 432, 694-706.

[2] L.Giglio, L.Boschetti, D.P.Roy, M.L.Humber, C.O Justice (2018) The Collection 6 MODIS burned area mapping algorithm and product. Remote sensing of environment, 217, 72-85.

[3] R.Ramo, M.García, D.Rodríguez, E.Chuvieco (2018) A data mining approach for global burned area mapping. International Journal of Applied Earth Observation and Geoinformation, 73, 39-51.

[4] A.M.Özbayoğlu, R.Bozer (2012) Estimation of the burned area in forest fires using computational intelligence techniques. Procedia Computer Science, 12, 282-287.

[5] J.Bedia, S.Herrera, J.M.Gutiérrez, A.Benali, S Brands, B.Mota, J.M.Moreno (2015) Global patterns in the sensitivity of burned area to fire-weather: Implications for climate change. Agricultural and Forest Meteorology, 214, 369-379.

[6] D.M.Fox, P.Carrega, Y.Ren, P.Caillouet, C. Bouillon, S.Robert (2018) How wildfire risk is related to urban planning and Fire Weather Index in SE France (1990-2013). Science of the Total Environment, 621, 120-129.

[7] J.Bedia, N.Golding, A.Casanueva, M.Iturbide, C. Buontempo, J. M. Gutiérrez (2018) Seasonal predictions of Fire Weather Index: Paving the way for their operational applicability in Mediterranean Europe. Climate Services, 9, 101-110.

[8] J.-S.R.Jang (1993) ANFIS: Adaptive-Network-based Fuzzy Inference Systems. IEEE Trans. On Systems, Man and Cybernetics, 23, 665-685.

\section{IZVOD}

\section{ANALIZA POVRŠINE POŽARA U ŠUMI PRIMENOM NEURO FAZU TEHNIKE}

Površina požara u šumi može da se analizira na bazi različitih ulaznih parametara kao i različitih kombinacija tih parametara. U ovom istraživanju je analizirana površina požara u šumi na osnovu različitih kombinacija ulaznih parametara. Glavni cilj je analizirati kako parametari utiču na površinu požara u šumi. ANFIS metodologija je korišćena u tu svrhu. Osam ulaznih parametara je korišćeno: FFMC, DMC, DC, ISI, temperatura, $R H$, vetar, kiša.

KIjučne reči: ANFIS; predikcijač površina požara; šuma.

Naučni rad

Rad primljen: 10. 11. 2018.

Rad prihvaćen: 08. 12. 2018.

Rad je dostupan na sajtu: www.idk.org.rs/casopis

(C) 2019 Authors. Published by Engineering Society for Corrosion. This article is an open access article distributed under the terms and conditions of the Creative Commons Attribution 4.0 International license (https://creativecommons.org/licenses/by/4.0/) 